\title{
COSTUME FISCAL E A NORMATIVIDADE DAS PRÁTICAS REITERADAS DA ADMINISTRAÇÃO: UMA LEITURA SISTÊMICA DO DIREITO TRIBUTÁRIO * \\ Rafael Köche
}

\author{
"FISCAL PRACTICE" AND THE NORMATIVITY OF \\ REPEATED PRACTICES OF PUBLIC ADMINISTRATION: \\ A SYSTEMIC ANALYSIS OF TAX LAW
}

\section{RESUMO}

O SENTIDO DE DETERMINADOS ATOS NORMATIVOS É MUITAS VEZES CONSTRUÍDO NO COTIDIANO, AO LONGO DO TEMPO, EM CERTO CONTEXTO HISTÓRICO BEM LOCALIZADO, DE FORMA DIFUSA E PULVERIZADA ENTRE OS ATORES SOCIAIS, SEM UMA INSTÂNCIA CENTRALIZADA DE DECISÃO QUE DECLARE O "SENTIDO OFICIAL" DE UMA LEI OU OUTRO ATO NORMATIVO QUALQUER. CASO SEMELHANTE OCORRE NO ÂMBITO TRIBUTÁRIO, EM QUE O SENTIDO DA NORMA MUITAS VEZES É DETERMINADO POR PRÁTICAS REITERADAS DAS AUTORIDADES ADMINISTRATIVAS, ISTO É, MUITOS CONTRIBUINTES PAUTAM SUAS DECISŌES A PARTIR DA FORMA COMO A AdMINISTRAC̣Ão PÚBliCA SE POSICIONA SOBRE DETERMINADO ASSUNTO. ASSIM, AINDA QUE NĀO HAJA UM ATO NORMATIVO QUE DISCIPLINE A POSIC̄ÃO DO FISCO, É POSSÍVEL DETERMINAR OS CRITÉRIOS JURÍDICOS QUE ELE UTILIZA, JUSTAMENTE PORQUE HÁ UMA RELACÃO (COMUnicativa) entre contribuintes e Fazenda Pública. ENTRETANTO, COM CERTA FREQUENCIA, MUITOS CONTRIBUINTES SÃO SURPREENDIDOS COM A ALTERAÇĀO REPENTINA DA POSIC̣ÃO SEDIMENTADA DO FISCO. NESSE SENTIDO, UMA NECESSÁRIA REFLEXÃO SE IMPÕE: OS EFEITOS DESSA ALTERAÇÃO DE CRITÉRIO JURÍDICO PODERIAM RETROAGIR? PODE A ÁdMINISTRAÇĀO TRIBUTÁrIA COBRAR RETROATIVAMENTE TRIBUTOS QUE ENTENDIA QUE NĀO ERAM DEVIDOS DAQUELA FORMA? O SENTIDO DA NORMA SÓ PODE SER DEFINIDO POR INSTÂNCIAS CENTRALIZADAS DE DECISĀO, OU ELE É CONSTITUÍDO TAMBÉM COM BASE NAS PRÁTICAS REITERADAS DOS ATORES SOCIAIS? É, A PARTIR

\section{ABSTRACT}

THE MEANING OF CERTAIN NORMATIVE ACTS IS OFTEN BUILT IN THE EVERYDAY LIFE, OVER TIME, IN A PARTICULAR HISTORICAL CONTEXT WELL PLACED, IN A DIFFUSE AND DISTRIBUTED WAY AMONG SOCIAL ACTORS, WITHOUT A CENTRALIZED INSTANCE OF DECISION THAT STATES THE "OFFICIAL MEANING" OF LAW OR ANY OTHER NORMATIVE ACT. A SIMILAR SITUATION TAKES PLACE IN THE CONTEXT OF TAXATION, IN WHICH THE MEANING OF THE NORM IS OFTEN DETERMINED BY REPEATED PRACTICES OF THE ADMINISTRATIVE AUTHORITIES, I.E., MANY TAXPAYING CITIZENS BASE THEIR DECISIONS UPON hoW the Public Administration stands on SPECIFIC ISSUE. THUS, ALTHOUGH THERE IS NO LEGISLATIVE ACT THAT DISCIPLINES THE POSITION OF THE TAX AUTHORITIES, IT IS POSSIBLE TO DETERMINE THE LEGAL CRITERIA IT USES, PRECISELY BECAUSE THERE IS A (COMMUNICATIVE) RELATIONSHIP BETWEEN TAXPAYING CITIZENS AND TAX AUTHORITIES. HOWEVER, OFTENLY MANY TAXPAYING CITIZENS ARE STRUCK BY A SUDDEN CHANGE OF "SEDIMENTED POSITION" OF THE TAX AUTHORITIES. IN THIS WAY, A NECESSARY REFLECTION ARISES: COULD THE EFFECTS OF THIS LEGAL CRITERIA CHANGE GO BACKWARDS? CAN THE TAX ADMINISTRATION RETROACTIVELY DEMAND TAXES WHEN IT DIDN'T CONSIDER THEM DUE IN THOSE TERMS? THE MEANING OF THE NORM CAN ONLY BE SET BY CENTRALIZED DECISIONMAKING INSTANCES, OR IS IT ALSO DEFINED BASED ON THE REPEATED PRACTICES OF SOCIAL ACTORS? IT IS 
DESSES QUESTIONAMENTOS, RELACIONANDO TEMPO E DIREITO, QUE ESTA INVESTIGAÇĀO SE PROPŌE A ESTABELECER PARÂMETROS INTERPRETATIVOS, PREOCUPADOS EM RESGUARDAR OS DIREITOS DAQUELES QUE TOMARAM SUAS DECISÕES COM BASE EM CRITÉRIO CONSIDERADO "LEGÍTIMO" E, AO MESMO TEMPO, FORTALECER A AdMINISTRAÇÃO TRIBUTÁRIA, A PARTIR DE FUNDAMENTOS DEMOCRÁTICOS.

\section{PALAVRAS-CHAVE}

DIREITO TRIBUTÁRIO; COSTUME FISCAL; ALTERAÇÃO DE CRITÉRIO JURÍDICO; RETROATIVIDADE; EFICÁCIA.

\begin{abstract}
BASED ON THOSE QUESTIONINGS, RELATING TIME WITH LAW, THAT THIS RESEARCH AIMS TO ESTABLISH CERTAIN INTERPRETATIVE PARAMETERS CONCERNED FOR SAFEGUARDING THE RIGHTS OF THOSE WHO MADE THEIR DECISIONS BASED ON A "LEGIT" CONSIDER CRITERIA AND, AT THE SAME TIME, FOR STRENGTHENING TAX ADMINISTRATION, FROM DEMOCRATIC FOUNDATIONS.
\end{abstract}

\section{KEYWORDS}

TAX LAW; FISCAL PRACTICE; NEW LEGAL STANDARD; RETROACTIVITY; ENFORCEABILITY.

\section{CONSIDERAÇÕES INICIAIS: UMA NECESSÁRIA CONTEXTUALIZAÇÃO}

Os sistemas brasileiros de fiscalização tributária estão entre os mais avançados do mundo - pelo menos, em nível federal. Ainda que se possa criticar a falta de recursos materiais e humanos no âmbito da Receita Federal do Brasil, por exemplo - crítica necessária, diante do número insuficiente de auditores fiscais para dar conta da crescente e cada vez mais complexa demanda; da infraestrutura inadequada em diversas unidades portuárias; da falta de espaço em armazéns ${ }^{1}{ }^{1}$, os instrumentos de fiscalização que estão sendo implementados nos últimos anos estão entre os mais avançados do mundo, desenvolvimento daquilo que se poderia denominar "tecnologia fiscal”. Ilustram esse avanço e modernização, com destaque especial, a Nota Fiscal Eletrônica e o Sistema Público de Escrituração Digital (SPED) - um sistema que está em funcionamento e será capaz de cruzar quase a totalidade dos dados relativos às operações diárias realizadas entre os contribuintes (empresas, entidades, profissionais liberais e consumidores). ${ }^{2}$

Nesse contexto de crescente fiscalização, os contribuintes ficam cada vez mais tensos e preocupados com a regularidade na prestação de informações. Repita-se: estamos falando da preocupação na regularidade da prestação das informações e não na regularidade das operações. Quem deliberadamente transgride a legislação tributária possui muitas razões para ficar preocupado; mas não é desses contribuintes que estamos tratando neste artigo. Estamos nos referindo àquele contribuinte que realiza suas operações (comerciais ou não), mas que, diante da complexidade das obrigações tributárias (principal e acessória), não sabe ao certo se as informações estão sendo prestadas da forma mais adequada - o que, consequentemente, implicará severas penalidades.

Além da complexidade das obrigações tributárias e da inevitável possibilidade de erros (ainda que formais), das elevadas multas aplicadas por descumprimento das obrigações (principal e acessória), dos sistemas de cruzamento de dados (que, muitas vezes, emite automaticamente o auto de lançamento no momento da transmissão dos arquivos digitais), há sempre a possibilidade de avaliar as operações do contribuinte em relação aos últimos cinco anos, constituindo e cobrando o respectivo crédito tributário. ${ }^{3}$ 
A fiscalização é necessária em qualquer instituição democrática. Democracia é também controle e justificação. Desse modo, não se está de forma alguma criticando a possibilidade de fiscalização das operações dos contribuintes. Ao contrário. Vemos a fiscalização não como uma possibilidade, mas como uma necessidade enquanto instância democrática. O que se quer retratar é a tensão permanente que empresários e seus contadores vivem diariamente para buscar cumprir com a legislação tributária (KÖCHE, 2012, p.3), além, é claro, de (tentar) se manter atualizado, diante da quantidade assustadora de normas tributárias publicadas por dia no Brasil. Para se ter a dimensão do que estamos tratando, um estudo realizado pelo Instituto Brasileiro de Planejamento Tributário (2012) ${ }^{4}$ levantou a quantidade de normas legais e infralegais publicadas desde a promulgação da Constituição em 1988 e constatou que mais de uma norma tributária é publicada por hora no País! É dizer: até para quem quer, não é fácil cumprir a legislação tributária no Brasil...

Feitas as devidas considerações, a partir do retrato acima, é possível perceber que existe certa insegurança cotidiana dos contribuintes (de boa-fé ou não). Em termos de estabilização social, o Direito busca minimizar o problema da insegurança a partir do princípio da legalidade, que poderia ser didaticamente desdobrado em dois sentidos, apenas para facilitar a compreensão. Numa primeira acepção, poderíamos dizer que ninguém é obrigado a fazer ou deixar de fazer alguma coisa senão em virtude de lei - é o que diz, por exemplo, o art. $5^{\circ}$, II, da Constituição Federal; e, em matéria tributária, poderíamos dizer que "é vedado à União, aos Estados, ao Distrito Federal e aos Municípios, exigir ou aumentar tributo sem lei que o estabeleça” (art. 150, I, da Constituição Federal). ${ }^{5}$ E, numa segunda acepção, poderíamos relacionar a legalidade com a noção de previsibilidade, uma vez que, de um modo geral, os efeitos da lei não retroagem - caso contrário, não haveria a possibilidade de se falar em segurança jurídica. Em matéria tributária, nesse sentido, poderíamos citar as disposições dos arts. 105 e 106 do Código Tributário Nacional, que determinam que "a legislação tributária aplica-se imediatamente aos fatos geradores futuros e aos pendentes" e que, apenas excepcionalmente, será aplicada a ato ou fato pretérito, nos casos em que beneficiar o contribuinte, por exemplo.

O problema que se coloca, pelo menos como objeto deste artigo, não é a ausência de lei, mas justamente a interpretação que lhe é conferida, ou seja, o critério jurídico empregado pela Administração Pública. Em outras palavras, quando um ato normativo é publicado por um dos Poderes do Estado, o sentido da norma não está contido no texto - ele é fruto de um escorço hermenêutico, com especial destaque ao papel do intérprete nesse contexto (STRECK, 2013, p. 333-374). Assim, muitas vezes, outros atos são expedidos para dar conta daquilo que se pode entender da lei; caso, por exemplo, das decisões judiciais, dos atos declaratórios interpretativos, das soluções de consulta sobre interpretação da legislação tributária, para ficarmos apenas nestes. 
Ocorre que nem sempre o sentido da lei e os critérios jurídicos definidos para sua aplicação e cumprimento são, como nos casos expostos acima, definidos por instâncias centralizadas de decisão. Nem sempre o sentido da lei é definido pelo desdobramento de um ato normativo ou por uma decisão administrativa ou judicial. Muitas vezes, os critérios jurídicos são definidos no cotidiano, ao longo do tempo, em determinado contexto histórico bem localizado, de forma difusa e pulverizada entre os atores sociais, sem uma instância centralizada de decisão que declare o "sentido oficial" de uma lei ou outro ato normativo qualquer.

É o que ocorre nos casos em que o sentido da norma é determinado por meio das práticas reiteradas das autoridades administrativas. Em outras palavras, muitos contribuintes pautam suas decisões a partir da forma como a Administração Pública se posiciona sobre determinado assunto. Diariamente, os contribuintes estão em contato com a Fazenda Pública para definir como proceder. Conversam com fiscais, chefes de departamento, técnicos do setor, outros contribuintes na mesma situação. Estabelecese uma "comunicação generalizada" 6 entre os atores envolvidos, sendo possível, ao longo do tempo, determinar a posição do Fisco sobre aquele assunto, os critérios jurídicos que ele utiliza.

Portanto, ainda que inexista documento formal que defina o "sentido oficial", os contribuintes conseguem determinar a posição da Fazenda Pública, dizendo quais os elementos essenciais para se configurar determinado fato gerador, quais são os requisitos para gozar determinado benefício fiscal, enfim, conseguem saber se estão cumprindo a lei, pelo menos na perspectiva do Fisco. Isso ocorre porque a comunicação não se reduz à expedição de atos normativos. As relações sociais são muito mais complexas do que isso.

Ocorre que, com alguma frequência, muitos contribuintes são surpreendidos com a alteração repentina da posição sedimentada do Fisco. Diante da "posição definitiva" dos tribunais superiores sobre determinado assunto, por exemplo, o Fisco busca rever sua posição a fim de se adequar ao "posicionamento oficial”, ciente de que suas decisões serão referendadas ou reformadas com base nessa decisão, uma vez que, no Brasil, apostamos na jurisdição constitucional. Poderíamos dizer de outro modo: a Teoria do Estado e da Constituição brasileira estabeleceu que o Poder Judiciário tem a competência de atribuir o sentido oficial dos atos normativos, além de ser o responsável pela jurisdição constitucional. Sendo o "intérprete oficial" de forma institucionalizada, sua decisão, ainda que totalmente desarrazoada, acaba sendo o "parâmetro interpretativo” para os demais Poderes, razão pela qual a Administração Pública, muitas vezes, altera os critérios jurídicos até então estabelecidos - ainda que estabelecidos de forma difusa, no âmbito das relações comunicacionais dos atores envolvidos, em especial, da relação Fisco/contribuintes.

Embora evidencie certa alteração de critério jurídico, a ilustração acima não pode ser entendida como um exemplo próprio do que estamos tratando. Que as práticas 
reiteradas são admitidas no Direito Tributário em caráter de norma complementar o próprio Código Tributário Nacional reconhece. Estamos problematizando práticas reiteradas da Administração que não se revestem das formalidades tão caras ao Direito Tributário, aquilo que denominamos de "comunicação generalizada", nos termos da Teoria Sistêmica (LUHMANN, 1983 e 2005; ROCHA; SCHWARTZ; CLAM, 2013; TEUBNER, 1993 e 2005). Nesse contexto, imaginemos duas situações hipotéticas:

(a) A cobrança de Imposto sobre Serviço de Qualquer Natureza (ISSQN) em regime especial (alíquota fixa por profissionais, por exemplo) depende da análise da municipalidade em relação a determinados requisitos. Aferido o cumprimento de tais requisitos, o município permite (por meio da alteração do cadastro municipal) que a empresa recolha o imposto na forma excepcional, sem expedir ato normativo que formalize essa "aprovação". Anualmente, o município renova tal cadastro, permitindo que a empresa pressuponha que ela preenche os requisitos (do ponto de vista formal).

(b) No âmbito do procedimento fiscal, os agentes analisam determinadas operações de uma empresa. Após a análise, realizam lançamento de ofício, sustentando a incidência de tributo sobre parte das operações analisadas. Considerando que o lançamento se deu apenas sobre parcela das operações, a empresa pressupõe que o tratamento tributário conferido às demais operações (que foram objeto de análise, mas não foram objeto de lançamento de ofício) está correto. Considerando que as empresas do mesmo segmento são fiscalizadas a partir do mesmo critério, não há expedição de ato normativo que determine as razões pelas quais o Fisco, em todas as fiscalizações que realiza, "deixa” de efetuar lançamento sobre aquela parte das operações.

Em ambos os casos, pela prática reiterada da Administração, é possível saber os critérios jurídicos que ela empregou para autorizar e renovar o cadastro de empresa em regime de tributação especial ou para que ela deixasse de efetuar lançamento tributário em relação a certas operações. Gize-se: em ambos os casos, não estamos diante da expedição de ato normativo formal. Em certa medida, a segunda hipótese aproximase muito da impossibilidade da chamada "revisão de lançamento" em relação à questão de direito (art. 146 do CTN).

Nesse sentido, uma necessária reflexão se impõe: os efeitos da alteração de critério jurídico poderiam retroagir? Pode a Administração Tributária cobrar retroativamente tributos que entendia que não eram devidos daquela forma? O sentido da norma só pode ser definido por instâncias centralizadas de decisão, ou ele é constituído também com base nas práticas reiteradas dos atores sociais? Em que a natureza das práticas é importante para pensar a retroatividade? Qual a peculiaridade das práticas reiteradas em relação às demais normas da legislação tributária para pensar sua aplicação no 
tempo? A mudança do critério jurídico de uma prática não significaria a mudança da própria prática?

A problematização dessas questões é o principal objetivo deste trabalho, que justamente se propõe a estabelecer certos parâmetros interpretativos, preocupados em resguardar os direitos daqueles que tomaram suas decisões com base em critérios considerados "legítimos" e, ao mesmo tempo, fortalecer a Administração Tributária, a partir de fundamentos democráticos. ${ }^{7}$

\section{i Complexidade, DUPla CONTINGÊnCia E EXPeCtativa nORMATiva}

A experiência humana pode ser analisada por diversas perspectivas, capazes de descrever as relações intersubjetivas em um determinado contexto histórico. Nesse sentido, as considerações a seguir poderiam partir da Antropologia, da Psicanálise, da Filosofia, enfim, de diversos aspectos que estão inter-relacionados, não excludentes entre si. Todas dariam conta de explicar as relações sociais de um certo modo, ainda que tal descrição não abarcasse toda a complexidade e contingência da sociedade transbordamento inevitável em qualquer análise que se pretenda fazer.

Desse modo, optamos por descrever interdisciplinarmente o fenômeno social por meio de uma análise eminentemente sociológica, ${ }^{8}$ pois, neste caso, a forma de narrativa escolhida dá conta de apresentar a problemática, sem ingressar em questões particularizadas da subjetividade, mas, antes disso, descrever as relações entre a sociedade e as organizações, em especial no âmbito do sistema do Direito. Em outras palavras, a análise não partirá do sujeito singularizado, enquanto indivíduo; não pretende propriamente avaliar as causas e os reflexos das relações sociais nos indivíduos. A análise se debruça sobre outro ponto de partida; e, claro, outro ponto de chegada: no estabelecimento de regras relativamente estáveis de entendimento da sociedade - ainda que esta seja radicalmente diferente -, ou daquilo que se convencionou chamar de "expectativas normativas".

Desse modo, partimos da noção de complexidade e contingência para descrever a sociedade. Uma sociedade é complexa porque as experiências "possíveis" são sempre muito mais numerosas que as experiências "efetivas". A decisão pressupõe a diferença; ou seja, outras decisões possíveis. Nesse sentido, a experiência implica sempre uma escolha, uma vez que a experiência efetiva necessariamente pressupõe que outras tantas experiências possíveis foram renunciadas. Além disso, a sociedade é contingencial porque toda experiência efetiva pode ser sempre diferente, e, nesse caso, está presente o "perigo de desapontamento e necessidade de assumir riscos" (LUHMANN, 1983, p. 48; ROCHA; SCHWARTZ; CLAM, 2013, p. 70). Em outras palavras, pode-se agir da mesma forma e necessariamente não atingir o mesmo resultado. ${ }^{9}$

O homem inevitavelmente desenvolve certas expectativas, sem as quais não poderia decidir nem agir diante da complexidade e contingência. Contudo, essas expectativas 
não são vinculativas, ou seja, estão sujeitas a desapontamentos e frustrações; é dizer: nem tudo vai ocorrer exatamente como se pensou. Quando isso ocorre, o homem pode reagir de duas formas: adaptar-se ao desapontamento, assimilando-o e reestabelecendo a expectativa; ou manter a expectativa, apesar da frustração. Classifica-se a primeira hipótese como um tipo específico de expectativa, a chamada expectativa cognitiva; a segunda hipótese, por sua vez, denomina-se expectativa normativa (LUHMANN, 1983, p. 56 seq.).

Note-se que, em ambas, se verifica o desapontamento, o desencontro dos fatos com as expectativas. Entretanto, as expectativas cognitivas estão sujeitas a sua própria revisão; isto é, a expectativa se adapta à complexidade e à contingência da experiência no mundo, restabelecendo-se constantemente. As expectativas normativas, no entanto, são "contrafactuais", justamente porque se mantêm "simbolicamente intactas", ainda em casos de desapontamentos; grosso modo, poder-se-ia dizer que, neste caso, a contingência e a complexidade da experiência no mundo se adaptariam à expectativa, e não o contrário.

Até aqui, verificou-se que a sociedade é complexa e contingente e que as organizações e as pessoas se inter-relacionam a partir de expectativas (cognitivas e normativas). Essa noção de expectativa torna-se mais complexa num contexto de intersubjetividade, pois, além das expectativas, a respeito da própria experiência, haverá também o que se pode denominar de "expectativa da expectativa" - ou seja, haverá a "dimensão do outro" na própria expectativa. O homem terá expectativas sobre a própria experiência com o outro, além de saber que suas expectativas geram expectativas no outro. Denomina-se “dupla contingência” esse duplo nível de expectativas (LUHMANN, 1983, p. 48). ${ }^{10}$

Desse modo, a complexidade pressupõe a incerteza de todo tipo de ação. Mesmo assim, ainda que haja certa imprevisibilidade das experiências (cognitivas), a sociedade não está mergulhada num verdadeiro caos. Ao contrário, há certa ordem nas relações sociais, pautadas na coordenação recíproca de expectativas, mediante a institucionalização comunicativa de expectativas comuns (LUHMANN, 2005, p. 639).

A noção de expectativa normativa, nesse sentido, faz muito bem essa função de estabilização das relações sociais, e o Direito acaba sendo o exemplo privilegiado dessa institucionalização, de uma estrutura de assimilação da experiência com o escopo de absorver e controlar a complexidade e contingência, permitindo certa qualidade no processo decisório - estabilizando os desapontamentos frente às expectativas. A estrutura do sistema jurídico, composta de expectativas comportamentais (dimensão temporal, dimensão social e dimensão prática) efetua uma seleção estrutural no sentido de cumprir com sua funcionalidade de, em situações de conflito, manter as expectativas comportamentais normativas. A operacionalidade do sistema é efetuada de maneira normativamente fechada, isto é, não se adaptando às possíveis desilusões. ${ }^{11}$

As normas jurídicas acabam sendo um produto institucionalizado da generalização das expectativas normativas realizada na comunicação social. Destarte, a coercibilidade 
não é o elemento primordial que diferencia as normas jurídicas - o que não significa que o Direito não possa se utilizar da violência para processar o desapontamento das expectativas normativas, mas a força do Direito reside no fato de ele ser uma práxis social, a sua obrigatoriedade adviria dessa generalização de expectativas normativas e não propriamente do monopólio de uma violência legítima (LUHMANN, 1983, p. 109 seq.).

É justamente a possibilidade do dissenso, da atitude contrária às expectativas normativas institucionalizadas, que nos faz considerar normal o comportamento divergente, um comportamento previsto pelo próprio direito e razão de ser deste, já que se não houvesse desrespeito às normas, estas seriam desnecessárias. O não direito é a outra face do direito, sendo ambos estabelecidos pelo sistema jurídico. ${ }^{12}$

Portanto, é possível concluir que o direito não se reduz a um "apanhado de textos". Para compreender a normatividade das regras jurídicas, é necessário compreender as expectativas normativas que estruturam o sistema jurídico, as quais fundamentaram todas as decisões - inclusive aquelas do cotidiano. Assim, é com base em tais premissas teóricas que se busca analisar as decisões administrativas - não em relação ao "mérito" propriamente dito (uma vez que, para isso, seria necessário um "estudo de caso" a ser arqueologicamente analisado), mas, sim, em relação à possibilidade de alteração dos critérios jurídicos que conformaram a decisão administrativa, também conhecida como "mudança de entendimento", e a possível retroatividade dos efeitos desse "novo entendimento" no âmbito tributário.

\section{Costume fiscal, PREVisibilidade e SEgURAnÇA JURÍdicA}

A Administração pode, a qualquer tempo, rever seus atos. Deve anulá-los, quando eivados de vícios de legalidade, e pode revogá-los por motivo de conveniência ou oportunidade, no âmbito da chamada "discricionariedade administrativa" - respeitados, é claro, os direitos adquiridos. ${ }^{13}$ Nota-se, todavia, que nos casos de anulação ou revogação há um determinado ato normativo bem definido a ser anulado ou revogado. A reflexão que estamos propondo não se debruça sobre textos normativos - sobre estes há muitos trabalhos a respeito (BALEEIRO, 1999, p. 811; PAULSEN, 2010 e 2009, p. 1020; COÊLHO, 2009, p. 708; DERZI, 2007, p. 299-325; e 2009b, p. 729-748) -, mas, sim, sobre uma certa "normatividade comportamental", ou seja, sobre a normatividade que se poderia extrair das práticas sociais reiteradas e consolidadas em determinado contexto histórico definido, sem, com isso, imobilizar a atuação da Administração Pública. ${ }^{14}$

Uma vez determinada a existência de uma prática reiterada da Administração Fazendária, a legislação impede a imposição de penalidades, a cobrança de juros de mora e a atualização do valor monetário da base de cálculo do tributo, caso ela altere seu entendimento acerca da matéria em questão, conforme assenta o art. 100, III 
e parágrafo único, do CTN. Entretanto, nos casos objeto do presente artigo e se analisadas as disposições do art. 146 do CTN, é possível questionar a exigência do próprio tributo, ${ }^{15}$ senão vejamos:

Lei n. 5.172/66: Art. 146. A modificação introduzida, de ofício ou em consequência de decisão administrativa ou judicial, nos critérios jurídicos adotados pela autoridade administrativa no exercício do lançamento somente pode ser efetivada, em relação a um mesmo sujeito passivo, quanto a fato gerador ocorrido posteriormente à sua introdução.

Uma necessária diferenciação deveria ser feita para poder estender os efeitos do art. 146 às disposições do art. 100, III, ambos do CTN, justamente em virtude de um instituto jurídico fundamental em Direito Tributário, qual seja: o lançamento. Não temos espaço neste artigo para realizar tais diferenciações dogmáticas. ${ }^{16}$ Mas é essencial deixar claro que estamos problematizando duas questões fundamentais, isto é, se poderíamos reconhecer juridicidade às comunicações generalizadas (Fisco/contribuintes) e se poderíamos questionar a exigência do próprio tributo em razão dessa alteração da prática administrativa reiterada.

Em outras palavras, reconhecendo a normatividade do costume fiscal e uma vez alterado o critério jurídico consolidado pela prática reiterada da Administração Fazendária, os efeitos retroagiriam apenas com relação às penalidades, ou também em relação ao próprio tributo? Considerando que o Direito Tributário é regido pelo princípio da estrita legalidade e pela necessária formalidade dos atos da Administração Pública, poderíamos entender como norma certas práticas comunicacionais consolidadas no tempo?

As questões lançadas não são de pequena importância. Uma empresa, por exemplo, ancorada nas orientações do Fisco, busca cumprir com a legislação tributária; define o preço dos serviços ou mercadorias com base na tributação a que está sujeita. Em outras palavras, a tributação compõe o custo. Se, após anos de legítima comunicação generalizada entre Fisco e contribuinte, constituída uma expectativa normativa de tal sorte que seja possível dizer que se trata de uma norma jurídica, a Administração Fazendária resolver alterar os critérios jurídicos em que se pautaram (Fisco e contribuintes) e cobrar os últimos cinco anos de tributos, comprometeria a própria existência de muitos contribuintes.

Por isso, Administração Fazendária e tributação não podem ser pensadas distante das noções de segurança jurídica, confiança e boa-fé. ${ }^{17}$ É crucial estabelecer regras claras que ofereçam segurança jurídica aos agentes econômicos envolvidos, no que tange à contabilidade comercial e fiscal, à administração, à fiscalização dos tributos e ainda ao sigilo bancário. A ideia de proteção da confiança não é senão o princípio da segurança jurídica na perspectiva do indivíduo, segundo a qual estes devem poder confiar seus direitos, posições e relações jurídicas tanto em relação a própria atuação 
como em relação à atuação das entidades públicas, considerando que as normas jurídicas devem se ligar a efeitos jurídicos duradouros (NABAIS, 1998, p. 395; CARRAZZA, 2009, p. 440-450).

Assim, podemos buscar responder às questões inauguradas no princípio deste artigo. A normatividade das práticas reiteradas não está propriamente na formalidade que as reveste (podendo, inclusive, inexistir ato formal para se configurar o costume fiscal). A natureza desse tipo de norma decorre de outro fator elementar: o tempo. É o tempo que consolida uma prática reiterada conferindo-a normatividade. É justamente em razão do tempo que a retroatividade dos efeitos da mudança da prática se tornaria problemática, eis que os efeitos da alteração de critério jurídico retroagiriam ao período que contribuiu para que a prática se conformasse em norma jurídica.

Ora, se os efeitos da alteração retroagissem no tempo, eles maculariam justamente o elemento que juridicizou determinada prática reiterada, que a tornou norma complementar em Direito Tributário. ${ }^{18} \mathrm{Na}$ prática, seria rechaçar a normatividade da norma, numa espécie de esquizofrenia jurídica. Por isso, a retroatividade da cobrança não é apenas um problema econômico de ordem privada, mas um problema de ordem eminentemente jurídica. A mudança do critério jurídico decorrente de uma prática reiterada significa a mudança da própria prática; assim, se a prática reiterada é norma jurídica, a mudança de prática implica alteração da norma jurídica, que, em Direito Tributário, deve respeitar o mínimo de previsibilidade, fundamental à segurança jurídica que norteia o Estado Democrático de Direito.

É reconhecer que o sentido das disposições legais se altera com o passar do tempo, que a Administração tem papel fundamental na "atribuição cotidiana de sentido" e que é possível identificar certa legitimidade nesse sentido constituído na práxis social, ainda que não haja um ato normativo expedido pelo respectivo órgão. Obviamente em outro contexto, Kelsen, numa interessante abordagem sobre a "criação do Direito", reconhecia a normatividade consuetudinária, uma vez que "o costume é um procedimento criador de direito no mesmo sentido que o é a legislação", todavia, uma "criação de Direito descentralizada":

A afirmação de uma regra consuetudinária se torna Direito apenas por meio de seu reconhecimento por parte das cortes que aplicam a regra, não é mais nem menos correta que a mesma afirmação feita com referência a uma regra decretada pelo órgão legislativo. Cada uma delas era Direito “antes de receber a chancela da autenticação judicial”, já que o costume é um procedimento criador de direito no mesmo sentido que o é a legislação. A diferença real entre Direito consuetudinário e Direito estatutário consiste no fato de que o primeiro é uma criação de Direito descentralizada ao passo que o segundo é uma criação de Direito centralizada. (KELSEN, 1997, p. $186-7)^{19}$ 
Nesse sentido, temos muito o que aprender com o Direito inglês, sem, no entanto, commonizar o Direito brasileiro. Ao contrário do que muitos sustentam, o Direito inglês não é um direito consuetudinário: "A common law teve por efeito fazer desaparecer o direito consuetudinário da Inglaterra, existente nos costumes locais” (DAVID, 2002, p. 441). ${ }^{20}$ A noção de costume (custom) desempenha um papel muito secundário no Direito inglês, não podendo se comparar à lei e à jurisprudência. ${ }^{21}$

Mesmo para a common law, o costume exposado enquanto prática reiterada não se constitui como direito, eis que ausente elemento fundamental para a tradição inglesa: a elaboração jurisprudencial submetida à regra do precedente. Desse modo, no âmbito deste trabalho, a aproximação possível está em relação à noção de prática usual, análoga às convenções constitucionais, à qual ninguém pensa em se esquivar. Assim, ainda que estejamos tratando do fenômeno jurídico a partir de um outro paradigma, algumas aproximações são possíveis para fins de ilustração - mas jamais podemos afirmar que estamos buscando uma espécie de sincretismo.

Além de anular e revogar seus próprios atos, a Administração pode alterar o seu entendimento sobre determinada matéria. É dizer: o sentido das coisas não está imune ao tempo. Ao contrário. Só é possível dizer que "algo e” em razão da historicidade em que ele inevitavelmente estará imerso: "O texto só é no seu contexto" (HEIDEGGER, 1997, p. 235). ${ }^{22}$ Entretanto, não é qualquer comunicação que se torna normativa. Há aqui a consideração a circunstâncias institucionais apropriadas que fazem com que a comunicação de determinado indivíduo seja considerada uma comunicação normativa, enquanto outra comunicação de conteúdo material idêntico, porém expedida em outras circunstâncias, não galgue esse status (VALVERDE, 2005, p. 195). Não basta uma mera expectativa para que esta seja institucionalmente aceita pelo Direito. É necessário algo mais que torne possível a generalização da expectativa de que todos aceitem a determinada comunicação, recebendo-a como norma jurídica.

Como adverte Luhmann, assim como há verdades que não adquirem a qualidade de científicas, recursos sem qualidade econômica e poder sem qualidade política, existem inúmeras expectativas normativas que não possuem qualidade jurídica. Muitas delas são processadas por outros sistemas normativos (moral, religião) e muitas outras são expectativas personalíssimas, que se limitam à vontade de certo indivíduo, não sendo possíveis de generalização. Seria inviável e inapropriado transformar todas elas em expectativas jurídicas. Por isso, o Direito cria mecanismos para fazer prevalecer apenas aquelas expectativas reputadas como as mais importantes, de acordo com um juízo que é axiológico e historicamente situado (VALVERDE, 2005, p. 195; LUHMANN, 2005, p. 38).

Então, se sabemos que a Administração Fazendária pode alterar os critérios jurídicos a respeito de determinado assunto - constatação inexorável -, o Direito deve dar subsídios mínimos de previsibilidade em relação às decisões administrativas, de modo a não deixar os contribuintes a mercê da discricionariedade, que, radicalizada 
nesse contexto, poderia ser sinônimo de arbitrariedade. Essa previsibilidade pode ser avaliada pela normatividade inerente aos textos legais e infralegais - mas também em relação ao que nos referimos como "normatividade comportamental”. Não há, pois, como negar normatividade às práticas reiteradas da fiscalização, ainda que inexistente qualquer tipo de ato formal.

Há um limite muito tênue entre uma expectativa individualizada e outra generalizada, de tal forma que se possa exigir a aplicação da lei de uma determinada forma (constituição de sentido), sem com isso romper com o Direito - e, sim, ampliar suas fontes tradicionais. É dizer: só é possível determinar a vinculatividade da Administração Fazendária (por meio da juridicização da expectativa normativa) no caso concreto.

Se, de um lado, a negação da normatividade às comunicações generalizadas entre Fisco e contribuintes, que elaborou uma legítima expectativa normativa capaz de proteger as relações jurídico-tributárias estabelecidas nessas bases, a mera retórica extraída da postura defendida neste trabalho pode ocasionar efeitos perversos em outro sentido. Ou seja, se, por um lado, protegeríamos a sociedade a partir desses pressupostos (de segurança jurídica e confiança permeada pela "normatividade comportamental"), abriríamos margem argumentativa - ainda que sob um manto meramente retórico - de contribuintes se valerem de posturas omissivas ou fraudulentas perpetradas pela Administração Fazendária para defender ilegalidades. Em outras palavras, reconhecemos o risco de, buscando conservar o status quo, certos contribuintes, por meio do raciocínio desenvolvido neste artigo, impedirem que a Administração Fazendária passe a cobrar tributos que não eram cobrados - não pela alteração de um critério jurídico (ambos legítimos), mas pela alteração de uma postura, que, muitas vezes, pode se revestir de mera omissão do Fisco, mas, em outras tantas, de corrupção dos agentes públicos.

Portanto, a irretroatividade dos efeitos do costume fiscal depende do cumprimento de certos requisitos. Em primeiro lugar, está condicionada a uma "legítima expectativa normativa”, isto é, para ser considerada legítima, a comunicação generalizada não pode contrariar a lei ou a Constituição Federal. Além disso, não se estará diante de uma alteração de norma geral abstrata infralegal em prol do contribuinte (situação já é disciplinada pelo Código Tributário Nacional); a norma jurídica, nesse caso, é decorrente de um agir reiterado diante de casos concretos. Por fim, em casos como os do exemplo inicial, a irretroatividade da alteração de critério jurídico em procedimento fiscal ("revisão de lançamento"), a irretroatividade não decorre de "questão de fato", mas de "questão de direito", para empregar a diferenciação feita pela doutrina brasileira dominante. ${ }^{23}$

As decisões tomadas pelo contribuinte, desse modo, são calculadas a partir das normas vigentes, incluindo nesse conceito não apenas as regras decorrentes do processo de criação legislativa, mas também aquelas decorrentes da práxis social. Por mais paradoxal que possa parecer, é justamente com base nessa noção “pulverizada” de normatividade que a segurança jurídica é possível, também como um critério de confiança. ${ }^{24}$ 
Legalidade, anterioridade, coisa julgada, ato jurídico perfeito, direito adquirido e proibição da retroatividade são apenas algumas das manifestações da confiança sistêmica, que permanece latente no Sistema do Direito, permitindo a rememoração do passado e a previsibilidade do futuro: "por isso que os sistemas contemporâneos têm dado relevante valor à confiança sistêmica, pois através dela é possível pensar nas mutações necessárias do Direito para adaptar-se à realidade social, mas com a previsibilidade e segurança jurídica para não distorcer o Sistema” (LOBATO, 2012, p. 50). ${ }^{25}$

No âmbito administrativo e tributário, a mesma constatação pode ser verificada: "o costume sendo de natureza eminentemente factual, só ingressa no ordenamento quando este, por meio do antecedente de uma norma, admiti-lo" (CARVALHO, 1998, p. 37). E de que modo a "normatividade do costume" ingressa no ordenamento jurídico? Por meio de regras institucionalizadas, como o caso da Lei n. 9.784/99, que regula as normas gerais aplicáveis aos processos administrativos no âmbito da Administração Pública Federal, no parágrafo único, XIII, do seu art. $2^{\circ}$, que "estabelece a irretroatividade de novas orientações administrativas”, e do Código Tributário Nacional, em seu art. 100, III, que afirma que as "práticas reiteradamente observadas pela autoridade administrativa são normas complementares” à legislação tributária. 26

Se, de algum modo, um "comportamento" se torna vinculativo, começamos a rever certos horizontes normativos em uma terra marcada pela herança da civil law e pela necessidade de um direito escrito, formal, devidamente juridicizado por meio de um órgão competente centralizado. Imaginemos isso ainda em uma área do Direito marcada pelo princípio da estrita legalidade e da necessária formalidade inerente a qualquer ato administrativo. Destarte, a afirmação de Kelsen anteriormente destacada faz sentido em um contexto que talvez o próprio autor não imaginou. Ou seja, estamos apontando para uma nova forma de compreensão do fenômeno jurídico e do próprio Direito, na linha trabalhada, por exemplo, por Gunther Teubner (2005). Estamos diante de uma nova compreensão dos influxos do tempo no Direito e na decisão administrativa. É nos limites epistemológicos traçados neste artigo que a tese esboçada faz sentido, devendo ser avaliada, caso a caso, a legitimidade da comunicação, em que as condições e circunstâncias historicamente definidas e bem localizadas podem ser avaliadas, de modo a estabelecer se as práticas reiteradas da Administração Fazendária vinculam sua decisão, tanto na imposição de penalidades quanto na apuração do tributo. 


\section{NOTAS}

* O presente trabalho foi realizado com apoio do CNPq, Conselho Nacional de Desenvolvimento Científico e Tecnológico - Brasil. A base deste texto foi objeto da monografia: "Expectativa normativa em direito público e o papel do Procurador do Estado: alteração de critério jurídico e a (ir)retroatividade dos efeitos em matéria tributária”, submetida à $3^{\text {a }}$ edição do Concurso de Monografias PGE-RS/APERGS, em 2013, no qual tirou a segunda colocação, recebendo o Prêmio APERGS Miguel Arcanjo da Rocha.

1 Nesse contexto, trabalho importante vem sendo realizado pelo Sindicato Nacional dos Auditores Fiscais da Receita Federal do Brasil (Sindifisco Nacional), que, além da defesa dos interesses da classe, ainda vem realizando estudos e propostas para a reestruturação do Sistema Tributário Nacional, de modo a torná-lo mais justo e igualitário. Cf. Sindifisco, 2010. No mesmo sentido: DIEESE, 2013.

2 Instituído pelo Decreto n. 6.022, de 22 de janeiro de 2007, o SPED faz parte do chamado Programa de Aceleração do Crescimento (PAC) do Governo Federal e constitui-se em um dos mais avançados sistemas de informatização da relação entre o Fisco e os contribuintes.

3 Estamos nos referindo ao prazo de decadência e prescrição previstos no Código Tributário Nacional, Lei n. 5.172/66, em seus arts. 173 e 174 .

4 De acordo com o estudo, elaborado em 2012, cerca de 6,3\% das normas editadas no Brasil se referem à matéria tributária. São 29.748 normas tributárias federais (10,2\% das normas tributárias), 89.461 normas tributárias estaduais (30,8\% das normas tributárias) e 171.723 normas tributárias municipais (59,0\% das normas tributárias). Isso significa que, em média, foram editadas 30 normas tributárias/dia ou 1,25 norma tributária por hora.

5 Há outras disposições constitucionais que poderiam ser citadas, como, por exemplo, o art. 97, que diz que: "Somente a lei pode estabelecer: I - a instituição de tributos, ou a sua extinção; II - a majoração de tributos, ou sua redução, ressalvado o disposto nos artigos 21, 26, 39, 57 e 65; III - a definição do fato gerador da obrigação tributária principal, ressalvado o disposto no inciso I do $\S 3^{\circ}$ do artigo 52, e do seu sujeito passivo; IV - a fixação de alíquota do tributo e da sua base de cálculo, ressalvado o disposto nos artigos 21, 26, 39, 57 e 65; V - a cominação de penalidades para as ações ou omissões contrárias a seus dispositivos, ou para outras infrações nela definidas; VI - as hipóteses de exclusão, suspensão e extinção de créditos tributários, ou de dispensa ou redução de penalidades”.

6 Por “comunicação generalizada” se está querendo evidenciar o caráter difuso e intersubjetivo envolvido nos processos de comunicação. Quando dizemos que uma comunicação torna-se simbolicamente generalizada, estamos, com isso, dizendo que ela não é produto de um sujeito singularizado, mas, sim, produto de uma série de relações difusas de conhecimento e poder, que, no caso do Direito, transcende a noção moderna de Política, conferindo-lhe normatividade (LUHMANN, 1985, p. 7-26). Por isso, quando reconhecemos que uma comunicação é simbolicamente generalizada (e o Direito opera a partir desse tipo de código), podemos decidir a partir de pressupostos normativos que nos permitem criar determinadas expectativas. A estabilização das expectativas acaba sendo um objetivo importante para o Direito quando pensamos que ele deve proporcionar segurança jurídica e confiança no âmbito das relações estabelecidas.

7 Essa discussão é relativamente recente em matéria tributária, pelo menos no Supremo Tribunal Federal. Misabel Derzi chega a dizer que foi com o Recurso Extraordinário n. 370.682-SC, cujo acórdão data de 15 fevereiro 2007, que "pela primeira vez, foi posta a indagação em matéria tributária" (DERZI, 2007, p. 301). No âmbito do direito público brasileiro, um dos autores pioneiros da análise entre Administração Pública e os princípios da segurança jurídica, confiança e boa-fé no País - e que, sem dúvida, merece destaque aqui - foi Almiro do Couto e Silva (2004a, p. 271-315; 2004b, p. 13-31; 2004c, p. 7-59).

8 A análise parte de marcos conceituais definidos pela teoria dos sistemas sociais autopoiéticos, visando descrever a sociedade como una, apesar de ser fracionada por sistemas comunicativos distintos. Nesse sentido, ver: LUHMANN, 2005 e 1983; TEUBNER, 1993 e 2005; ROCHA, 2003; e ROCHA; SCHWARTZ; CLAM, 2013.

9 "Com complexidade queremos dizer que sempre existem mais possibilidades do que se pode realizar. Por contingência entendemos o fato de que as possibilidades apontadas para as demais experiências poderiam ser diferentes das esperadas; ou seja, que essa indicação pode ser enganosa por referir-se a algo inexistente, inatingível, ou algo que após 
tomadas as medidas necessárias para a experiência concreta [...] não mais está lá. Em termos práticos, complexidade significa seleção forçada, e contingência significa perigo de desapontamento e necessidade de assumir-se riscos." (LUHMANN, 1983, p. 45). Ademais, "la distinción que constituye a la complejidad tiene la forma de una paradoja: la complejidad es la unidad de una multiplicidad. Un estado de cosas se expresa en dos versiones distintas: como unidad y como multiplicidad - y el concepto rechaza que se trate aquí de algo distinto. Con esto se bloquea la salida fácil que consiste en hablar de complejidad a veces como unidad y a veces como multiplicidad" (LUHMANN, 2005, p. 101).

10 "Sob as condições da dupla contingência, portanto, todo experimentar e todo agir social possui uma dupla relevância: uma ao nível das expectativas imediatas de comportamento, na satisfação ou no desapontamento daquilo que se espera do outro; a outra em termos de avaliação do significado do comportamento próprio em relação à expectativa do outro. $\mathrm{Na}$ área de integração entre esses dois planos é que deve ser localizada a função do normativo - e assim também do direito." (LUHMANN, 1983, p. 48)

11 Nesse diapasão, em uma sociedade complexa e contingente, as possibilidades de comportamento social exigem reduções que tendem a possibilitar a manutenção de expectativas comportamentais recíprocas, as quais são orientadas a partir das expectativas sobre expectativas. Assim, por meio deste controle, seriam reduzidos os riscos de frustrações de expectativas. Desse modo, Luhmann assevera que "la función del derecho tiene que ver com expectativas", em razão de a normas jurídicas constituírem "un entramado de expectativas simbolicamente generalizadas" (LUHMANN, 2005, p. 182-6).

12 Partindo de uma perspectiva da Teoria dos Sistemas, podemos dizer que o direito não mais justifica sua obrigatoriedade apoiando-se na moral, na religião, ou na possibilidade de aplicação de uma sanção, mas sim na estrutura das expectativas estabilizadas, ou seja, o direito fundamenta sua imposição por meio da rede de expectativas que as pessoas atribuem umas às outras.

13 Art. 53 da Lei n. 9.784/99: “Art. 53. A Administração deve anular seus próprios atos, quando eivados de vício de legalidade, e pode revogá-los por motivo de conveniência ou oportunidade, respeitados os direitos adquiridos". Na mesma linha, disciplina o Verbete Sumular n. 473 do Supremo Tribunal Federal: "A Administração pode anular seus próprios atos, quando eivados de vícios que os tornam ilegais, porque deles não se originam direitos; ou revogá-los, por motivo de conveniência ou oportunidade, respeitados os direitos adquiridos, e ressalvada, em todos os casos, a apreciação judicial”.

14 É isso o que normalmente está por trás das conhecidas “mudanças de entendimento", "alterações de critério jurídico", "nova interpretação". Por isso, repetimos: não estamos buscando imobilizar a atuação administrativa muito antes, pelo contrário. Após a leitura atenta dos referenciais teóricos trabalhados neste artigo, uma afirmação desse tipo seria uma infundada acusação de recairmos justamente no estamos criticando.

15 Nesse sentido, Ives Gandra afirma: “Tenho para mim que o art. 146 do CTN já de ser entendido em consonância com o art. 100 do CTN, sempre à luz do princípio da irretroatividade constitucional. O art. 100 do CTN nitidamente é voltado à orientação contra a lei, em que o contribuinte não pode ser apenado por seguir interpretação incorreta" (MARTINS, 2007, p. 17). Ver também: DERZI, 2009a.

16 O lançamento tributário é regido pelo princípio da inalterabilidade, ou seja, uma vez realizado não pode mais sofrer modificação pela autoridade administrativa (art. 146 do CTN). Entretanto, algumas exceções foram previstas e elencadas nos incisos I, II e III do art. 145, que alude: "O lançamento regularmente notificado ao sujeito passivo só pode ser alterado em virtude de: I - impugnação do sujeito passivo; II - recurso de ofício; III - iniciativa de ofício da autoridade administrativa, nos casos previstos no artigo 149". Para entender quando a administração poderá alterar um lançamento realizado, faz-se necessário diferenciar o instituto do "erro de direito" e o instituto do "erro de fato". Ver, para tanto: CARRAZZA, 2009, p. 423-425; e BALEEIRO, 1999, p. 809-815. Em poucas palavras, o "erro de direito" ocorre quando há mudança ou substituição do critério jurídico relativo ao fato gerador, que poderá levar a Administração a alterar o lançamento realizado. Entretanto, essa alteração só poderá ser aplicada para os fatos que ocorreram depois da mudança, devendo retroagir somente se for para beneficiar o contribuinte (MACHADO, 2001, p. 147). Isso não é novidade. A Súmula n. 227 do extinto TFR (Tribunal Federal de Recursos) afirmava que: "A mudança de critério jurídico adotado pelo fisco não autoriza a revisão do lançamento”.

17 Essa constatação se torna ainda mais relevante quando nos defrontamos com a concepção de Pérez Luño, que afirma que há uma aproximação inevitável entre segurança e justiça. (PÉREZ LUÑO, 1990, p. 335) 
18 Em relação ao tempo, a decisão pode se dar de duas maneiras, na linha que aborda Leonel Severo Rocha. Ela pode estar voltada para o futuro, produzindo tempo e diferença (programação finalística); ou voltada para o passado, negando o tempo, produzindo repetição (programação condicional). Nesse sentido, quando alguém produz diferença, emprega o que se pode denominar de programação finalística, frustrando as expectativas normativas na sociedade (LUHMANN, 2005, p. 126).

19 Quando nos referimos a Kelsen, não estamos necessariamente referendando sua elaboração epistemológica; o que se reconhece é a importância do autor na elaboração da Teoria do Direito brasileiro. Desse modo, a constatação kelseniana lançada no texto acaba se destacando por duas razões principais: em virtude da sua antecipação, mas principalmente por sabermos o quanto de Kelsen "existe" no modo como entendemos o Direito no País. Desse modo, ao se desenvolver uma Teoria Crítica do Direito, a partir de novos paradigmas, o autor de Teoria Pura do Direito inevitavelmente deve ser enfrentado. Nesse sentido, ver: FERRAZ Jr. 1994, p. 93-254 e 1998, p. 68-219; ROCHA, 1985, p. 8-26; 1984, p. 57-75; 1999, p. 121-136; e WARAT, 1995, p. 37-62.

20 Há muitos enganos acerca da common law e o direito inglês: "Antes de tudo o mais, devemos abandonar a ideia tão corrente de que o direito inglês é um direito consuetudinário. [...] Em segundo lugar, devemos abandonar a ideia de que a legislação é, no direito inglês, uma fonte de importância secundária. [...] Na verdade, a Inglaterra não tem códigos, mas o ‘direito escrito’ é tão importante e está tão desenvolvido como no continente europeu. [...] Em terceiro lugar, devemos abandonar a ideia de um regra do precedente aplicada com automatismo e paralisante da evolução do direito inglês" (DAVID, 2002, p. 441-3).

21 "Atualmente, o costume desempenha uma função muito restrita no direito inglês. Toda a função importante lhe é retirada por uma regra que exige que o costume, para que seja obrigatório, tenha o caráter de costume imemorial. [...] O costume geral imemorial do reino, sobre o qual teoricamente está fundada a common law, sempre foi uma simples ficção. A common law pôde retirar algumas das suas regras dos vários costumes locais outrora em vigor, porém o processo em si de constituição da common law consistiu em elaborar um direito jurisprudencial, fundado sobre a razão, que substituísse o direito da época anglo-saxônica, fundado sobre o costume." (DAVID, 2002, p. 437) "Quando um costume é consagrado pela lei ou pela jurisprudência, ele perde seu caráter de costume, tornando-se uma regra jurisprudencial submetida à regra do precedente." (DAVID, 2002, p. 407-8)

22 É justamente com base na noção de finitude, historicidade e facticidade, que Martin Heidegger dirá que o tempo é o nome do ser (HEIDEGGER, 1997, p. 235). 'Em 'Ser e Tempo' 'ser' não é outra coisa que 'tempo', na medida em que 'tempo' é designado como prenome para a verdade do ser, prenome cuja verdade é o acontecimento (Wesende) do ser e assim o próprio ser” (HEIDEGGER, 1997. p. 83). Este artigo, todavia, não se propõe a aprofundar o modo como a compreensão se dá e como seria possível determinar a validade da compreensão no âmbito jurídico. Para tanto, ver: KÖCHE, 2012.

23 Rechaçamos tal diferenciação, uma vez que consideramos que toda questão de direito é uma questão de fato; mas optamos por trabalhar a partir dessa categoria para simplificar a compreensão das questões lançadas.

24 Quando nos referimos à noção de trust (confiança), estamos nos referindo a noção desenvolvida por autores como García de Enterría (1998). Tal ressalva se faz necessária, uma vez que, ao fazermos diversas aproximações com a common law, o leitor poderia confundir essa noção de trust com o instituto jurídico desenvolvido no âmbito do direito inglês a partir da equity. Sobre este aspecto, ver: DAVID, 2002, p. 384-407.

25 “Os princípios da protecção da confiança e da segurança jurídica podem formular-se assim: o cidadão deve poder confiar em que aos seus actos ou às decisões públicas incidentes sobre os seus direitos, posições jurídicas e relações, praticados ou tomadas de acordo com as normas jurídicas vigentes, se ligam os efeitos jurídicos duradouros, previstos ou calculados com base nessas mesmas normas. Estes princípios apontam basicamente para: (1) a proibição de leis retroactivas; (2) a inalterabilidade do caso julgado; (3) a tendencial irrevogabilidade de actos administrativos constitutivos de direitos" (CANOTILHO, 1995, p. 373). “A estabilidade ou eficácia ex post da segurança jurídica: uma vez adoptadas, na forma e procedimento legalmente exigidos, as decisões estaduais não devem poder ser arbitrariamente modificadas, sendo apenas razoável alteração das mesmas quando ocorram pressupostos materiais particularmente relevantes. (2) previsibilidade ou eficácia ex ante do princípio da segurança jurídica que, fundamentalmente, se reconduz à exigência de certeza e calculabilidade, por parte dos cidadãos, em relação aos efeitos jurídicos dos actos normativos” (ibidem, p. 380).

26 É justamente a partir desse tipo de parâmetro que a noção de “fontes do direito”, em especial, do Direito 
Tributário, pode ser compreendida e que esse excerto se justifica. Nesse sentido, ver: GRAU, 1975, p. 56. Esse critério vem sendo adotado, em certa medida, pela jurisprudência das cortes superiores (cf. REsp 162.616/CE, Recurso Especial n. 1998/0006152-5, Rel. Min. José Delgado, órgão julgador: Primeira Turma, data do julgamento: 02.04.1998, data da publicação/fonte: DJ 15.06.1998, p. 53, RSTJ v. 107 p. 85. Ementa: "Tributário. Prática reiterada de atos pela administração. Penalidade inaplicável. Inteligência do art. 100, inc. III, par. único, do CTN. 1. Restando configurada a prática constante de atos pela Administração, há de se aplicar o preceito insculpido no art. 100, III, par. único, do CTN, que exclui o contribuinte da imposição de Penalidades, da cobrança de juros de mora e a atualização do valor Monetário da base de cálculo do tributo. 2. Recurso improvido”; REsp 98.703/SP, Recurso Especial n. 1996/0038538-6, Rel. Min. Ari Pargendler, órgão julgador: Segunda Turma, data do julgamento: 18.06.1998, data da publicação/fonte: DJ 03.08.1998, p. 179, RSTJ v. 113, p. 124. Ementa: "Tributário. Práticas administrativas. Se o contribuinte recolheu o tributo a base de prática administrativa adotada pelo Fisco, eventuais diferenças devidas só podem ser exigidas sem juros de mora e sem atualização do valor monetário da respectiva base de cálculo (CTN, art. 100, III c/c par. único). Recurso especial conhecido e provido, em parte" (grifo nosso).

\section{REFERÊNCIAS BIBLIOGRÁFICAS}

BALEEIRO, Aliomar. Direito tributário brasileiro. 11. ed. atual. Misabel de Abreu Machado Derzi. Rio de Janeiro: Forense, 1999.

CANOTILHO, J. J. Gomes. Direito constitucional. 6. ed. Coimbra: Almeida, 1995.

CARRAZZA, Roque Antonio. Curso de direito constitucional tributário. 25. ed. São Paulo: Malheiros, 2009.

CARVAlHO, Paulo de Barros. Curso de direito tributário. São Paulo: Saraiva, 1998.

COÊLHO, Sacha Calmon Navarro. Curso de direito tributário brasileiro. Rio de Janeiro: Forense, 2009.

DAVID, René. Os grandes sistemas do direito contemporâneo. Trad. Hermínio A. Carvalho. 4. ed. São Paulo:

Martins Fontes, 2002.

DERZI, Misabel de Abreu Machado. Modificações da jurisprudência no direito tributário: proteção da confiança, boa-fé objetiva e irretroatividade como limitações constitucionais do poder judicial de tributar. São Paulo: Noeses, 2009a.

A Irretroatividade do Direito, a Proteção da Confiança, a Boa-fé e o RE nº 370.682-SC. In: Valdir de Oliveira Rocha. (Org.). Grandes questões atuais do direito tributário. Vol. 11. São Paulo: Dialética, 2007, p. 299-325.

. Mutações jurisprudenciais, em face da proteção da confiança e do interesse público no planejamento da receita e da despesa do estado. In: FERRAZ, Roberto (Org.). Princípios e limites da tributação. Vol. II. São Paulo: Quartier Latin, 2009b, p.729-748.

DIEESE. 10 ideias para uma tributação mais justa. São Paulo: DIEESE. 2013. Disponível em:

<http://www.dieese.org.br/cartilha/2013/10ideias_completo.pdf>. Acesso em: 22 nov. 2013.

ENTERRIA, Eduardo Garcia de. Democracia, jueces y control de la administración. 4. ed. Civitas: Madrid, 1998.

FERRAZ JR., Tercio Sampaio. Função social da dogmática jurídica. São Paulo: Max Limonad, 1998.

Introdução ao estudo do direito. Técnica, decisão e dominação. 2. ed. São Paulo: Atlas, 1994.

GRAU, Eros Roberto. Conceito de tributo e fontes do direito tributário. São Paulo: Resenha Tributária, 1975.

HEIDEGGER, Martin. Conferências e escritos filosóficos. Trad. Ernildo Stein. São Paulo: Nova Cultural, 1997. INSTITUTO BRASILEIRO DE PLANEJAMENTO TRIBUTÁRIO (IBDT). Quantidade de normas editadas no Brasil: 24 anos da Constituição Federal de 1988. Estudo coordenado por Gilberto Luiz do Amaral, João Eloi Olenike e Letícia M. Fernandes do Amaral. Curitiba, 2012. Disponível em: <http://www.ibpt.com.br/ $\mathrm{img} /$ uploads/novelty/estudo/70/Em24AnosDeConstituicao46MilhoesDeNormasCriadas.pdf >. Acesso em: 22 nov. 2013.

KELSEN, Hans. Teoria pura do direito. 5. ed. Trad. João Baptista Machado. São Paulo: Martins Fontes, 1997. KÖCHE, Rafael. Elementos de hermenêutica filosófica para a compreensão do fenômeno jurídico. Trabalho de Conclusão de Curso. Curso de Graduação em Direito. Universidade do Vale do Rio dos Sinos (Unisinos). 2012 .

Obrigações acessórias ameaçam a atividade empresarial contábil. Jornal do Comércio, JC

Contabilidade, Porto Alegre, 26 set. 2012, p. 3. 
LOBATO, Valter Souza. O princípio da confiança retratado no Código Tributário Nacional. A aplicação dos artigos 100 e 146 do CTN. A análise de casos concretos. Revista Brasileira de Direito Tributário e Finanças Públicas, Porto Alegre, v. 6, n. 35, p. 42-70, nov.-dez. 2012.

LUHMANN, Niklas. El derecho de la sociedad. 2. ed. Trad. Javier Torres Nafarrate, Brunhilde Erker, Silvia Pappe e Luis Felipe Segura. Ciudad de México: Herder; Universidad Iberoamericana, 2005.

Poder. 2. ed. Brasília: Editora Universidade de Brasília, 1985.

. Sociologia do direito. Tradução Gustavo Bayer. Vol. I. Rio de Janeiro: Tempo Brasileiro, 1983.

MACHADO, Hugo de Brito. Curso de direito tributário. 19. ed. São Paulo: Malheiros, 2001.

MARTINS, Ives Gandra da Silva. O princípio da não cumulatividade no IPI - inteligência da Lei n. 9.799/1999 em face do princípio - direito ao aproveitamento do crédito de tributos em operações finais imunes, isentas ou sujeitas à alíquota zero - Parecer. Revista de Estudos Tributários, n. 56, jul.-ago. 2007.

NABAIS, José Casalta. O dever fundamental de pagar impostos. Coimbra: Almedina, 1998.

PAULSEN, Leandro. Curso de direito tributário. 3. ed. Porto Alegre: Livraria do Advogado, 2010.

Direito tributário: Constituição e Código Tributário à luz da doutrina e da jurisprudência. 11. ed.

Porto Alegre: Livraria do Advogado, 2009.

PÉREZ LUÑO, Antonio Enrique. Seguridad jurídica y sistema cautelar. Doxa: Publicaciones periódicas, Alicante, n. 7, p. 327-349, 1990. Disponível em:

<www.cervantesvirtual.com/servlet/SirveObras/01371630233495944102257/cuaderno7/doxa7_12.pdf>.

Acesso em: 14 out. 2013.

ROCHA, Leonel Severo. A problemática jurídica: uma introdução transdisciplinar. Porto Alegre: SAFE, 1985. Epistemologia jurídica e democracia. 2. ed. São Leopoldo: Unisinos, 2003.

O sentido político da Teoria Pura do Direito. Revista Sequência, Florianópolis, n. 9, p. 57-75, jun. 1984. Três matrizes da teoria jurídica. In: ROCHA, Leonel Severo; STRECK, Lenio Luiz; MORAIS, Jose Luis

Bolzan (Org.). Anuário do Programa de Pós-Graduação em Direito da Unisinos, 1999. São Leopoldo: Unisinos, 1999

; SCHWARTZ, Germano; CLAM, Jean. Introdução à teoria do sistema autopoiético do direito. 2. ed. Porto

Alegre: Livraria do Advogado, 2013.

SILVA, Almiro do Couto e. O princípio da segurança jurídica (proteção à confiança) no direito público brasileiro e o direito da administração pública de anular seus próprios atos administrativos: o prazo decadencial do art. 54 da Lei do Processo Administrativo da União (Lei n. 9.784/99). Revista de Direito Administrativo, Rio de Janeiro, n. 237, p. 271-315, jul.-set. 2004a.

O princípio da segurança jurídica (proteção à confiança) no direito público brasileiro e o direito da administração pública de anular seus próprios atos administrativos: o prazo decadencial do art. 54 da Lei do Processo Administrativo da União (Lei n. 9.784/99). RBDP, Belo Horizonte, ano 2, n.6, p. 7-59, jul.-set. 2004 b. Princípios da legalidade da administração pública e da segurança jurídica no estado de direito contemporâneo. RPGE, Porto Alegre 27 (57): p. 13-31, 2004c.

SINDIFISCO. Sistema Tributário: diagnósticos e elementos de mudanças. Brasília, 2010. Disponível em: <http://www.sindifisconacional.org.br/mod_download.php?id=aHR0cDovL3d3dy5zaW5 kaWZpc2NvbmFja W9uYWwub3JnLmJyL2ltYWdlcy9lc3R1ZG9zL3Npc3RlbWFfdHJpYnV0YXJpby9Fc3R1ZG9UcmlidXRhcmlv X2NvbXBsZXRvLnBkZnww>. Acesso em: 16 set. 2013.

STRECK, Lenio Luiz. Hermenêutica jurídica e(m) crise. 11. ed. Porto Alegre: Livraria do Advogado, 2013.

TEUBNER, Günther. Direito, sistema e policontexturalidade. Piracicaba: Unimep, 2005. . O direito como sistema autopoiético. Lisboa: Calouste Gulbekian.1993.

VALVERDE, Gustavo Sampaio. Segurança jurídica e processo: recursos, coisa julgada, ação rescisória e ações de (in)constitucionalidade. In: SANTI, Eurico Marco Diniz de (Coord.). Curso de especialização em direito tributário. Rio de Janeiro: Forense, 2005.

WARAT, Luis Alberto. O direito e sua linguagem. Porto Alegre: SAFE, 1995.

\section{Rafael Köche}

São Leopoldo - RS - Brasil rafakochelagmail.com
MEMBRO DO GRUPO DE PESQUISA TRIBUTACÃO E DIGNIDADE HUMANA (CNPQ/UNISINOS).

Mestre em diREITO PELA Universidade do VALE do RIO dos SINOS (UNISINOS) COM BOLSA DE MESTRADO DO CNPQ-BRASIL. 